\title{
Clinical and experimental approaches for imaging of acute kidney injury
}

\author{
Daisuke Katagiri $^{1,2}\left(\right.$ Feng Wang $^{3,4} \cdot$ John C. Gore $^{4} \cdot$ Raymond C. Harris $^{1} \cdot$ Takamune Takahashi $^{1,4}$
}

Received: 23 November 2020 / Accepted: 17 March 2021 / Published online: 9 April 2021

(c) The Author(s) 2021

\begin{abstract}
Complex molecular cell dynamics in acute kidney injury and its heterogeneous etiologies in patient populations in clinical settings have revealed the potential advantages and disadvantages of emerging novel damage biomarkers. Imaging techniques have been developed over the past decade to further our understanding about diseased organs, including the kidneys. Understanding the compositional, structural, and functional changes in damaged kidneys via several imaging modalities would enable a more comprehensive analysis of acute kidney injury, including its risks, diagnosis, and prognosis. This review summarizes recent imaging studies for acute kidney injury and discusses their potential utility in clinical settings.
\end{abstract}

Keywords Acute kidney injury · Imaging techniques · Damage biomarkers

\section{Introduction}

The incidence of acute kidney injury (AKI), a serious and common problem associated with a high mortality rate, is increasing [1-5]. The risk of chronic kidney disease (CKD) and end-stage renal disease (ESRD) increases by 8.8 -fold and 3.3-fold, respectively, in surviving and discharged patients with AKI [6]. To enable early AKI recognition and sufficient response, several damage biomarkers in the blood and urine have been identified and evaluated [7].

Imaging techniques targeting renal diseases have recently been developed, with each imaging modality having particular characteristics: some have the advantage of clinical

Daisuke Katagiri

dkatagiri@hosp.ncgm.go.jp

$\triangle$ Takamune Takahashi

takamune.takahashi@vumc.org

1 Division of Nephrology and Hypertension, Vanderbilt University Medical Center, S-3223 MCN, Nashville, TN 37232, USA

2 Department of Nephrology, National Center for Global Health and Medicine, 1-21-1 Toyama, Shinjuku-ku, Tokyo 162-8655, Japan

3 Vanderbilt University Institute of Imaging Science, Vanderbilt University Medical Center, Nashville, TN, USA

4 Vanderbilt In Vivo Mouse Kidney Imaging Core, Vanderbilt University Medical Center, Nashville, TN, USA translation, whereas others have the disadvantages of high cost or long scan time [8]. The current review aimed to discuss potentially useful and noninvasive imaging techniques targeting AKI as a comprehensive functional biomarker (Table 1) and to explore the possibility of combining them with novel damage biomarkers. The techniques for imaging AKI are as follows: (1) visualize structural renal abnormalities related to CKD underlying AKI [9]; (2) detect urinary tract obstruction, which accounts for $3-10 \%$ of AKI [10, 11]; (3) evaluate renal perfusion, oxidation, apoptosis, and fibrosis in each kidney with three-dimensional spatial information; (4) provide noninvasive assessment of the entire kidneys, including the associated organs such as the renal artery, as opposed to renal biopsy, which is invasive and analyzes only a limited portion of kidneys; and (5) evaluate distant organs such as the lungs because remote organ damage in AKI is well known [12]. Investigating currently available imaging techniques both in clinical and basic settings is worthwhile because most of the imaging techniques can be translated into clinics.

\section{Molecular mechanisms of acute kidney disease}

Numerous factors affect the outcome of AKI, including insult type, hemodynamic alternations, age, underlying CKD, interventions, and genetic variation $[5,13,14]$. 
Table 1 Currently available imaging techniques for AKI evaluation in clinical or experimental settings

\begin{tabular}{|c|c|c|}
\hline & Evaluation & Modality \\
\hline \multirow[t]{3}{*}{ Clinical imaging } & Renal structure and vasculature & Ultrasonography \\
\hline & & CT \\
\hline & Inflammation & PET-CT with ${ }^{18}$ F-FDG \\
\hline \multirow[t]{18}{*}{ Basic imaging } & Renal structure and vasculature & Ultrasound \\
\hline & & Micro-CT \\
\hline & & $\mathrm{T}_{1^{-}}$and $\mathrm{T}_{2}$-weighted MRI \\
\hline & Renal Pathology & Cationic ferritin-enhanced MRI \\
\hline & Blood flow, blood volume, and urine flow & Dynamic contrast-enhanced MRI \\
\hline & & Fluorine-19 MRI \\
\hline & & Hemodynamic response imaging \\
\hline & & Pulsed arterial spin labeling \\
\hline & & Renal scintigraphy \\
\hline & Oxygenation & Blood oxygenation level-dependent MRI \\
\hline & Metabolism & $\begin{array}{l}\text { Magnetic resonance spectroscopic imaging } \\
\text { Chemical exchange saturation transfer }\end{array}$ \\
\hline & & PET-CT with ${ }^{18}$ F-FDG \\
\hline & Fibrosis & Diffusion-weighted imaging \\
\hline & & Magnetization transfer \\
\hline & & Magnetic resonance elastography \\
\hline & & Spin-lattice relaxation time in the rotating frame \\
\hline & Sodium imaging & ${ }^{23} \mathrm{Na} \mathrm{MRI}$ \\
\hline & Molecular imaging & $\begin{array}{l}\text { Targeted superparamagnetic iron oxide nanoparticles } \\
\text { Targeted microbubble contrast agents } \\
\text { Optical molecular probes or reporters }\end{array}$ \\
\hline
\end{tabular}

$C T$ computed tomography, $F D G{ }^{18} \mathrm{~F}$-fluorodeoxyglucose, $M R I$ magnetic resonance imaging

Several therapies for AKI have been developed in an effort to explore targets in pathways; however, no attractive therapies are recommended for use in the AKI setting to date [15]. Biochemically, the degree of hypoxia, oxidative stress, cell cycle arrest, suppression of mitochondrial biogenesis, and epigenetic changes contribute to AKI extension [13]. Renal endothelial injury and dysfunction play a pivotal role in the initiation and extension phases of epithelial injury [16]. In ischemic settings, epithelial cells are unable to maintain intracellular ATP, reducing effective perfusion and eventually leading to necrosis or apoptosis [17]. Infiltrating mononuclear phagocytes play an important role in AKI initiation and progression, as well as tissue repair [18, 19]. Dendritic cells and colony-stimulating factor-1-dependent macrophages produce mediators that induce tissue repair after AKI [20]. Cellular repair processes are initiated and organ integrity is reestablished during the maintenance phase [21].With severe or repeated damage to the renal proximal tubules beyond the adaptive repair potential or in the context of abnormal conditions, chronic inflammation, vascular rarefaction, or glomerular sclerosis will subsequently occur, leading to interstitial myofibroblast development [22]. Fibrosis and scarring with a reduction in renal functional mass confirm post-AKI "progression" [16].

\section{Clinical imaging approaches for AKI}

\section{Ultrasonography (US)}

B-mode US is a noninvasive examination routinely conducted on patients with AKI that provides anatomical information about the kidneys, including size (or echogenicity, to distinguish AKI from CKD), hydronephrosis (to rule out post-renal AKI due to urinary tract obstruction), calcification, and cysts [23-25]. As the incidence of urinary tract obstruction is lower in patients with hospitalacquired AKI than in those with community-acquired AKI [26], it is preferable to consider the risk of hydronephrosis, including recurrent urinary tract infections, prior to the performance of US in hospitalized patients with AKI $[27,28]$. US enables Doppler-based assessment of resistive index and pulsatility index, which are associated with renal artery and blood flow disorders and persistent or intrinsic AKI $[29,30]$. Both indexes are usually obtained by transabdominal or translumbar US; transesophageal US can also be used to assess the resistive index in patients undergoing cardiac surgery for the evaluation of predictable postoperative AKI [31]. Contrast-enhanced US 
performed with a microbubble-destruction technique [32] is employed for the assessment of patients with septic shock; considering that reduced blood flow in the renal cortex correlates with AKI severity, contrast-enhanced US may become more accurate in evaluating renal perfusion, as it can detect a $15 \%$ reduction in normal renal blood flow $[33,34]$. US elastography is a currently developing technique that can evaluate renal stiffness [35]. Derieppe et al. [36] reported that renal cortical stiffness measured by US elastography correlated with proteinuria. Although this "stiffness" includes not only fibrosis but also anisotropy, vascularization, or hydronephrosis [35], US elastography can be translated into the sequential assessment of maladaptive fibrosis after severe AKI.

\section{Computed tomography (CT)}

CT provides accurate images of small organs. Diagnosis of atherosclerotic renal artery stenosis with $\mathrm{CT}$ angiography is well known, but it is inapplicable to AKI due to the risk of contrast-induced AKI [37]. Experimentally, micro-CT had been shown in mice to have the potential to noninvasively monitor a transplanted kidney's configuration and function [38].

\section{Positron emission tomography (PET)-CT with ${ }^{18} \mathrm{~F}$-fluorodeoxyglucose (FDG)}

FDG is a tracer for glucose metabolism with a well-established utility in cancer imaging. FDG accumulates in not only tumor cells but also macrophages, lymphocytes, neutrophils, and fibroblasts in inflammatory lesions [39]. The diagnostic performance of PET-CT with FDG for inflammatory conditions such as perirenal abscess, vasculitis, and drug-induced acute interstitial nephritis has been reported [40-44].

\section{Basic imaging approaches for AKI}

\section{Renal structure and vasculature}

\section{Ultrasound}

An advanced noninvasive ultrasound system can identify microvessels. Chen et al. [45] have recently reported the use of super-resolution ultrasound scan to assess microvascular changes, including size, blood volume (BV), and vessel density, after ischemia-reperfusion injury (IRI)-AKI in live mice.

\section{Micro-CT}

Micro-CT technology and radiopaque perfusion compounds have enabled the acquisition and three-dimensional quantification of renal vascular structure and volume in preclinical models [46]. A previous study reported a reduction in MECA-32-positive peritubular capillaries from day 1, preceded by fibrosis, in an IRI mouse model [47]. While micro-CT cannot examine the capillary structure, a new contrast agent that can make this possible has recently been developed [48]. The structure of renal capillaries can also be assessed using fluorescence microangiography. Kramann et al. [49] reported the loss of peritubular capillary densities after AKI using fluorescence microangiography with renal artery injection.

\section{$T_{1}$ - and $T_{2}$-weighted magnetic resonance imaging (MRI)}

The protocols of $T_{1}$ - and $T_{2}$-weighted MRI and magnetization transfer contrast MRI have been optimized to acquire high-resolution, high-contrast imaging data of normal and diseased kidneys. Traditional $T_{1}$ or $T_{2}$ values on MRI have been investigated in patients with AKI. Previous studies using a unilateral IRI-AKI mouse model reported prolonged $T_{1}$ and $T_{2}$ values due to cell swelling and interstitial edema in the cortex and outer and/or inner medullary stripes [50,51].

\section{Renal pathology}

\section{Cationic ferritin-enhanced magnetic resonance imaging (CF-MRI)}

CF-MRI has been used to assess glomerular number and size. Recent reports have shown that this technique could be used for assessing renal pathology in AKI or AKI to CKD transition, including structural changes in glomeruli and renal lesion $[52,53]$.

\section{Blood flow, BV, and urine flow}

MRI provides anatomical and functional details. Functional MRI has been developed to noninvasively examine renal function and pathology [54-56].

\section{Dynamic contrast-enhanced MRI}

Several currently available imaging techniques can evaluate renal blood flow in AKI [57]. Dynamic contrast-enhanced MRI, which uses iron oxide nanoparticles or gadoliniumbased contrast agents with low molecular weight, can determine the spatial distribution of renal perfusion and vascular reactivity [55, 58-60]. Of note, single-kidney GFR/ split function can be estimated using this method [61]. 
Nevertheless, gadolinium-based techniques are difficult to apply in the setting of human renal dysfunction because of the risk of nephrogenic systemic fibrosis [62, 63].

Intravascular superparamagnetic iron oxide (SPIO) nanoparticles do not undergo glomerular filtration and have a long plasma half-life. Previous studies reported the use of these nanoparticles for BV assessment in both rat and mouse models, as well as their application to patients with CKD [64-66]. In this context, a recent experimental study has shown that capillary rarefaction is more closely associated with AKI-to-CKD progression than renal fibrosis [67]. This imaging technique may be effectively used for assessing AKI-to-CKD progression and for tracking and monitoring the distribution of specific cells (e.g., mesenchymal stem cells) in the AKI setting [68].

\section{Fluorine-19 MRI}

In addition to ${ }^{1} \mathrm{H}$ MRI, fluorine-19 MRI can be employed to quantify changes in blood partial pressure of oxygen $\left(\mathrm{pO}_{2}\right)$ and BV in kidneys $[60,69]$. The application of fluorinated emulsions prepared from perfluorocarbons to examine BV fraction and $\mathrm{pO}_{2}$ in the renal microvasculature has been explored using mice with AKI [70].

\section{Pulsed arterial spin labeling (ASL)}

Pulsed ASL techniques label the arterial blood supplying the tissue of interest by altering its longitudinal magnetization $[71,72]$, and their utility in assessing tissue perfusion, including in transplanted allografts, without the use of contrast agents has been reported [73]. However, these techniques may have limitations in the AKI setting owing to the long scan time [74]. A previous study showed the application of ASL imaging for the measurement of renal cortex perfusion in an IRI mouse model [75].

\section{Renal scintigraphy}

Renal scintigraphy with injection of tracers such as ${ }^{99 \mathrm{~m}} \mathrm{Tc}$ mercaptoacetyltriglycine (MAG3), ${ }^{99 \mathrm{~m}} \mathrm{Tc}$-diethylenetriaminepentaacetic acid (DTPA), and ${ }^{99 \mathrm{~m}} \mathrm{Tc}$-dimercaptosuccinic acid (DMSA) can evaluate human renal function [76, 77]. The MAG3 tracer is extracted from the kidney through secretion from the proximal tubules, allowing for the evaluation of renal plasma low, tubular function, and urine excretion [78]. Previous studies using ${ }^{99 \mathrm{~m}} \mathrm{Tc}-\mathrm{MAG} 3$ dynamics reported long-term alterations in renal function after IRIAKI in mice $[79,80]$.

${ }^{99 \mathrm{~m}} \mathrm{Tc}$-DMSA is up-taken by renal tubules, enabling the assessment of renal morphology, structure, and function. Dysfunction of megalin/cubilin results in the cessation of renal uptake of a1-microglobulin-bound 99mTc-DMSA and increased urinary excretion [81]. The use of ${ }^{99 \mathrm{~m}} \mathrm{Tc}-\mathrm{DMSA}$ and ${ }^{99 \mathrm{~m}} \mathrm{Tc}-\mathrm{MAG} 3$ for cortex imaging and dynamic renography, respectively, in mice with cisplatin-induced AKI has been reported [82]. ${ }^{99 \mathrm{~m}} \mathrm{Tc}-\mathrm{DMSA}$ was used to evaluate the effects of remote preconditioning in renal function of IRI kidneys [83]. ${ }^{99 \mathrm{~m}} \mathrm{Tc}-\mathrm{DTPA}$ is cleared from the plasma through glomerular filtration and is not absorbed or secreted by the tubules, enabling the measurements of single-kidney GFR.

\section{Oxygenation}

As a result of the lower blood flow in the medulla and the countercurrent arrangement that permits oxygen diffusion from arteries to veins, the ambient $\mathrm{pO}_{2}$ in the renal medulla is very low $(<20 \mathrm{mmHg})$ and is even lower than that in systemic venous blood $(\sim 40 \mathrm{mmHg})$. The medullary thick ascending limbs (MTALs) contribute to the osmotic gradient by active sodium reabsorption, which requires much oxygen [84]. Hypoxia reduces the ability of tissues to function (i.e., hypoxic injury) [85]. In particular, segment 3 renal proximal tubule cells are highly sensitive to hypoxia in the AKI setting because of low oxygen pressure [86] associated with high energy consumption by ATP-consuming transporters [87, 88]. Post-AKI interstitial fibrosis with impairment in oxygen diffusion is consistently associated with CKD [89].

\section{Blood oxygenation level-dependent (BOLD) MRI}

BOLD contrast reflects the presence of deoxyhemoglobin in the bloodstream, which changes the signal of protons from the water molecules surrounding a blood vessel [90]. The ratio of oxyhemoglobin, which has no major magnetic property, to deoxyhemoglobin, which is strongly paramagnetic, is proportional to $\mathrm{pO}_{2}$. The BOLD signal is estimated using the transverse relaxation rate $\left(R_{2}{ }^{*}=1 / T_{2}{ }^{*}\right)$ as an indicator of tissue $\mathrm{pO}_{2} . T_{2}{ }^{*}$ relaxation time decreases as the deoxyhemoglobin concentration in the blood increases, followed by a decrease in BOLD signal intensity. The utility of BOLD MRI for measuring renal tissue oxygenation, particularly extracellular oxygen tension such as in the bloodstream, has been reported [57, 91]. BOLD MRI is effective in evaluating changes with pharmacological or physiological manipulations, including furosemide, water load, and vasoactive substances [92, 93]. Additionally, BOLD MRI has been reported in IRI-AKI and CI-AKI models [69, 94, 95]. Hofmann et al. [96] reported that post-AKI changes in $R_{2}{ }^{*}$ values were induced by several drugs, including indomethacin, radiocontrast media, cyclosporine, and tacrolimus. Furthermore, chronological $T_{2}{ }^{*}$ and $T_{2}$ mapping after IRI-AKI in a rat model has been reported [97]. It has also been applied for allograft status evaluation in kidney recipients $[98,99]$. Because BOLD MRI is an overall index of the combined 
effects of oxygen delivery (renal blood flow, extracellular oxygen tension), oxygen consumption (sodium transport in tubules), hydration status, and arteriovenous diffusion [93, 100], caution should be exercised when interpreting BOLD MRI signals from an ailing kidney in complex situations such as AKI and CKD [101].

The quantitative BOLD approach is based on a mathematical model of BOLD contrast [102] and has been mainly evaluated in neuroimaging, although its ability to assess steady-state local basal oxygen saturation should be useful in monitoring time-dependent renal hypoxia in the AKI setting [103]. Different from conventional BOLD MRI, the quantitative BOLD approach provides more specific parameter $\mathrm{SO}_{2}$ to evaluate local blood oxygen saturation. Nevertheless, this approach has not been clinically established because of the long acquisition time required [104]. A functional BOLD MRI technique, called hemodynamic response imaging, in which transient alterations in inspired gases from normoxia to hypercapnia and subsequently to hyperoxia enable the evaluation of renal oxygenation, perfusion, and vascular reactivity, has been reported in AKI and CKD models [105]. In addition to BOLD MRI, Hirakawa et al. [106] have recently reported a new technique for quantifying intracellular oxygen tension in an IRI mouse model by measuring the phosphorescence lifetime of small luminescent molecular probes.

\section{Tissue injury}

\section{Diffusion-weighted imaging (DWI)}

DWI utilizes the difference in water molecule motion between tissues as the image contrast and can thus be rapidly performed without the administration of exogenous contrast agents. This technique senses changes in water molecule motion at the cellular level and provides qualitative and quantitative information that reflects cell membrane integrity (cell damage), cellularity, fibrosis, and perfusion.

DWI measures the apparent diffusion coefficient (ADC), which provides information on quantitative diffusion properties and the contribution of microcirculation in kidneys [74], and has been reported in animal models of unilateral AKI and contrast agent nephropathy [95, 107-109]. Inoue et al. [110] showed the application of ADC to a group of patients with AKI. Another clinical study indicated its usefulness in evaluating allograft function shortly after kidney transplantation and reported significantly lower ADC in transplanted kidneys undergoing acute rejection or acute tubular necrosis [111].

Diffusion tensor imaging provides diffusion measurements (e.g., fractional anisotropy, axial and radial diffusivity) for the evaluation of diffusion changes in different directions and can be applied to renal allograft assessment, as it provides information on the preferred diffusion direction, directed diffusion degree, and renal microstructure [112]. An intravoxel incoherent motion (IVIM) model based on diffusion-weighted images acquired at different $b$-values has been proposed to separate the effects of blood microcirculation perfusion from those of tissue diffusion $[113,114]$. The perfusion fraction in AKI on IVIM imaging is affected by several conditions, including cast accumulation in tubules [115].

\section{Metabolism}

Certain metabolic dysfunctions such as amino acid, purine, taurine, and choline dysregulations have been identified in CKD rat models [116]. Notably, the characterization of certain metabolites in AKI is informative and one of the strengths of the imaging field. For instance, the production of renal fumarate metabolite, which increases in necrotic cells, is detectable with ${ }^{13} \mathrm{C}$ magnetic resonance spectroscopic imaging in mice with folic acid-induced AKI [117].

\section{Chemical exchange saturation transfer (CEST) imaging}

CEST MRI displays the interactions between solute protons including amine, amide, or hydroxyl groups that resonate at specific spectral components and can be used to image important metabolic parameters that change in diabetic kidney disease (e.g., intracellular proteins, $\mathrm{pH}$, levels of metabolites such as glycogen, glycosaminoglycan, and glutamate) [118]. Using a db/db endothelial nitric oxide synthase knockout model, we evaluated the utility of CEST imaging in assessing the progression of diabetic nephropathy and identified CEST effects corresponding to relative glucose/ glycogen levels [119]. Longo et al. reported the use of CEST MRI with iopamidol for measuring temporary $\mathrm{pH}$ elevation in both kidneys in several AKI mouse models [120,121]. CEST MRI has also been applied in a lipopolysaccharideinduced septic AKI mouse model [122].

\section{${ }^{18} \mathrm{~F}-\mathrm{FDG}$ PET/CT}

Reuter et al. [123] reported a series of ${ }^{18}$ F-FDG accumulations in cases of acute rejection of allogeneically transplanted kidneys ameliorated by immunosuppressive therapy in mice. Furthermore, this PET imaging has been applied to examining delayed graft function and AKI in post-renal transplant patients [124]. While ${ }^{18} \mathrm{~F}$-FDG accumulation is not specific to certain cells, ${ }^{18} \mathrm{~F}$-FDG labeling of isolated leukocytes can discriminate the rejection of allogeneically transplanted kidneys from IRI, acute cyclosporine toxicity, or responses to syngeneically transplanted kidneys [125]. 


\section{Fibrosis}

Previous studies investigated CKD progression with persistent interstitial fibrosis, followed by maladaptive processes $[126,127]$. Proximal tubule injury beyond the adaptive repair potential will arrest epithelial cells in the G2/M transition of the cell cycle and will enhance the production of profibrotic factors [22, 128]. Repeated or rambling renal damage results in extracellular matrix accumulation and tubular atrophy, eventually leading to hypoxia and interstitial fibrosis in kidneys $[67,129,130]$. Thus, assessing the degree of renal fibrosis in patients with AKI will be crucial to their treatment. DWI or BOLD imaging can be used to assess renal fibrosis [110, 131-133]; however, factors other than fibrosis (e.g., blood flow) can change ADC or $R_{2}{ }^{*}$. Hence, a more fibrosis-specific imaging method is required to precisely assess renal fibrosis.

\section{Magnetization transfer (MT)}

MT can detect large immobile macromolecules distributed within tissues and evaluate pathophysiological events (e.g., fibrosis, apoptosis) accompanied by changes in macromolecular components. We and others have recently shown that renal fibrosis can be assessed using specific parameter pool-size ratio from the quantitative MT approach based on mathematical modeling or MT ratio from simpler two-point metrics [132, 134-136]. Importantly, changes in physiological conditions and hemodynamics can affect measurements on DWI and BOLD imaging, even in the absence of fibrosis. However, MT measures remain the same during functional changes in kidneys [137].

\section{Magnetic resonance elastography (MRE)}

Similar to US elastography, MRE is an MRI modality that enables visualization of tissue elasticity and is sensitive to fibrotic changes [132, 133]. Nonetheless, its specificity and sensitivity to detect interstitial fibrosis may not be high because other factors such as tubular damage and renal blood flow also affect MRE-derived stiffness [138].

\section{Spin-lattice relaxation time in the rotating frame (T1rho)}

The use of spin-lattice relaxation time in the rotating frame (T1rho) for renal fibrosis assessment has recently been shown $[139,140]$. T1rho imaging is a new MRI technique that can sensitively detect macromolecules, including collagen and proteoglycans [141], and may also be used for renal fibrosis assessment in patients with AKI.

\section{Sodium imaging}

AKI may lead to insufficient oxygen utilization for tubular sodium transport [100]. Sodium $\left({ }^{23} \mathrm{Na}\right)$ MRI provides a direct measure for determining the tissue sodium concentration (TSC) [142, 143]. In normal kidneys, the sodium signal intensity gradually increases from the cortex to the inner medulla. Atthe et al. [144] reported impairment in sodium reabsorption due to acute tubular necrosis after moderate-to-severe IRI-AKI in rats. TSC was more prominently decreased in the medulla, especially the outer medulla and MTALs, than in the cortex. Marill et al. [142] reported significantly reduced TSC in the inner medulla in a model of contrast medium-induced AKI, in which necrosis was limited to only $4 \%$ of MTALs.

\section{Molecular imaging}

Specific molecular events during AKI can be assessed using MRI or ultrasound imaging with targeted contrast agents. Akhtar et al. [145] conjugated a vascular cell adhesion protein-1 (VCAM-1) monoclonal antibody to $1-\mu \mathrm{m}$ iron oxide microparticles in order to visualize and define the threedimensional distribution of VCAM-1 expression after IRIAKI in rats. SPIO nanoparticles are notable in AKI owing to the absence of contrast-induced AKI risk associated with the use of iodinated contrast medium. The use of ultrasound with enzyme-loaded nanospheres to detect oxidative stress after IRI has been reported [146]. Recently, microbubble contrast agents have been improved to ligand-specific monoclonal antibodies such as P-selectin and VCAM-1, which were reported to be evaluated in rats with IRI [147]. Furthermore, optical molecular renal probes sensitive to $\mathrm{N}$-acetyl$\beta$-D-glucosaminidase and caspase-3 have been developed for real-time imaging and shown to be useful in detecting the early stage of drug-induced AKI in mice [148]. Photoacoustic Imaging techniques allow us to obtain more deep tissue information compared to traditional optical imaging. The recently reported Fluoro-photoacoustic Reporter is designed to look at the activity of gamma-glutamyl transferase (GGT) that was excreted from damaged tubules in AKI [149].

\section{Utility of imaging techniques in the diagnosis and treatment of AKI}

Actions are worthy to be undertaken during the "incipient AKI" phase prior to the occurrence of "clinical AKI," which is currently based on sCre elevation [150]. The duration of this short-term therapeutic window and the clinical period of AKD, including AKI, are highly important for predicting kidney prognosis [151]. Because the "incipient AKI" phase can lead to diverse outcomes, from full recovery to several 
clinical AKI stages, it should be carefully investigated using damage biomarkers, urine microscopy findings, and imaging techniques (Fig. 1). Imaging techniques may aid in detecting changes in the microcirculation or tissue oxygenation, and subsequent detection of novel biomarkers may indicate the susceptibility of renal epithelial cells to injury (Table 2). In particular, imaging methods such as CEST imaging or SPIO nanoparticles can help to evaluate sCre-negative but damage biomarker-positive patients with subclinical or incipient AKI [152]. Privratsky et al. [59] reported renal tissue damage detection using dynamic contrast-enhanced MRI after cisplatin treatment from an early stage when sCre and NGAL levels were not elevated. In the context of clinical settings, cutoff values for novel damage biomarkers and imaging information need to be evaluated against patient outcomes (e.g., need for renal replacement therapy) independent of functional biomarkers (e.g., sCre) [13, 153].

Thus far, several large prospective multicenter trials failed to show the sufficient performance of these novel damage biomarkers for clinical use [154-157]. The

Fig. 1 Overall strategy for assessing AKI in different stages. Throughout the course of AKI, patients should be assessed using functional biomarkers (BM) including sCre or BUN, damage BM, urine microscopy, and various imaging techniques
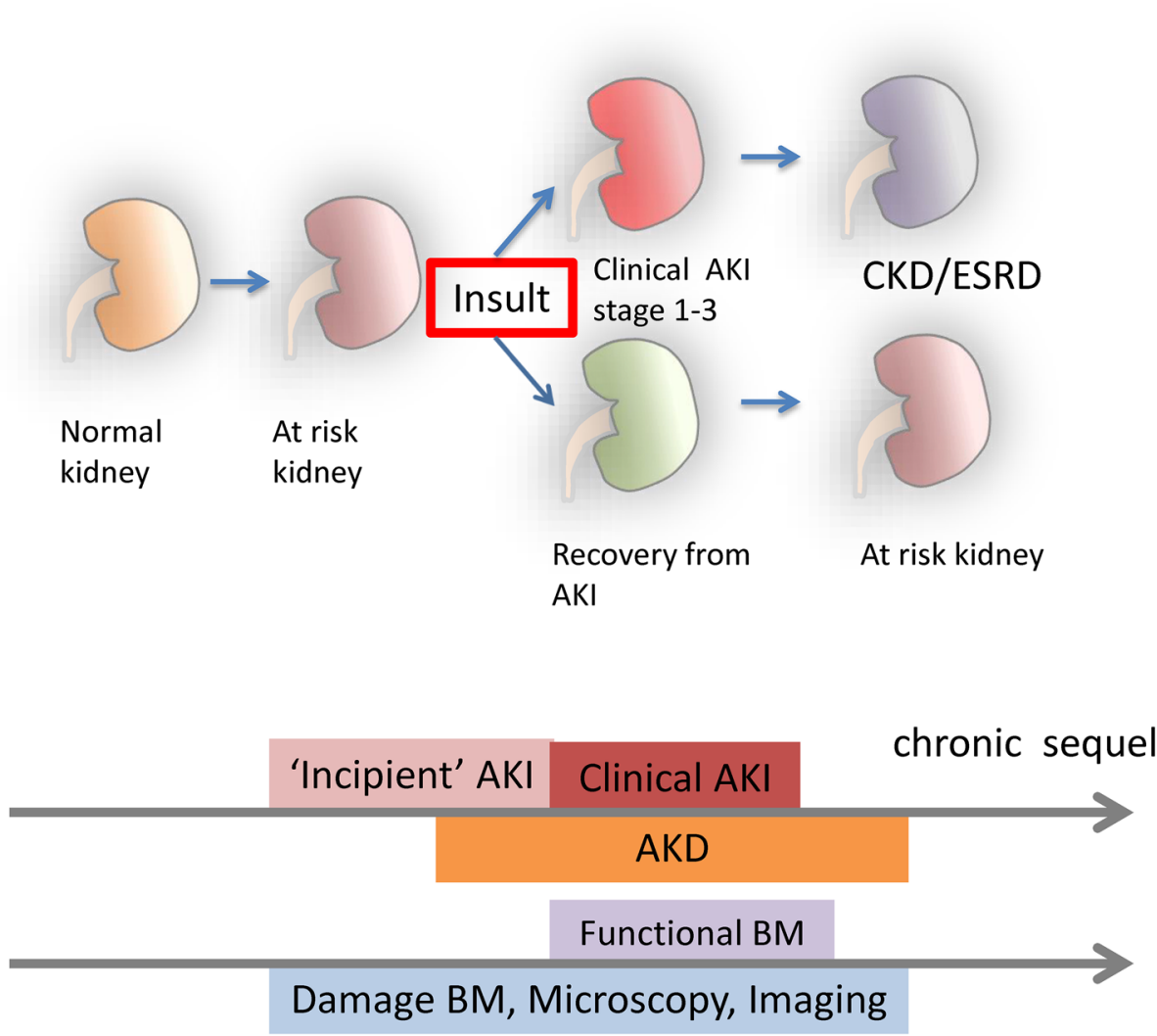

Table 2 Suggested strategy for assessing responses to AKI: combine novel biomarkers and emerging imaging techniques to detect incipient AKI and evaluate its extension, recovery, or progression to CKD

\begin{tabular}{|c|c|c|c|c|c|}
\hline & \multicolumn{2}{|l|}{ Incipient AKI } & \multirow{2}{*}{$\begin{array}{l}\text { Clinical AKI } \\
\text { AKI extension (or host } \\
\text { response) }\end{array}$} & \multirow[t]{2}{*}{ Adaptive repair } & \multirow[t]{2}{*}{ Maladaptive repair } \\
\hline & At-risk kidney & Insult, development & & & \\
\hline Functional biomarkers & & & Creatinine, urine output & & \\
\hline Damage biomarkers & & NGAL, L-FABP, KIM-1 & $\begin{array}{l}\text { NGAL, L-FABP, TIMP-2, } \\
\text { IGFBP-7 }\end{array}$ & MCP-1, UMOD, YKL-40 & NGAL, KIM-1 \\
\hline Imaging & US, MRI & BOLD & CEST, ${ }^{23} \mathrm{Na}$ MRI, SPIO & CEST, BOLD & qMT, DWI \\
\hline Others & & Sediment & Kinetic eGFR & & \\
\hline
\end{tabular}

$B O L D$ blood oxygenation level-dependent, $C E S T$ chemical exchange saturation transfer, $D W I$ diffusion-weighted imaging, $e G F R$ estimated glomerular filtration rate, IGFBP insulin-like growth factor-binding protein, $K I M-1$ kidney injury molecule-1, $L$-FABP L-type fatty acid-binding protein, $M R I$ magnetic resonance imaging, NGAL neutrophil gelatinase-associated lipocalin, $q M T$ quantitative magnetization transfer, SPIO superparamagnetic iron oxide, TIMP-2 tissue inhibitor of metalloproteinase-2, US ultrasonography, MCP-1 Monocyte Chemotactic Protein-1, UMOD Uromodulin, $Y K L-40$ Chitinase-3 like protein 1 
Fig. 2 Multi-parametric MRI that may aid in assessing AKI. The top diagams indicate changes in biomarkers (BM) during the course of AKI. The top diagrams were adapted from the $A D Q I$ XIII Work Group. J Am Soc Nephrol. 2015 [13]. The lower charts indicate multi-parametric imaging that can help determine the fibrotic area in maladaptive repair after kidney insult in the absence of an ideal repair biomarker. $q M T$ quantitative magnetization transfer, $D W I$ diffusionweighted imaging, SPIO superparamagnetic iron oxide
Clinical AKI with

Adaptive Repair
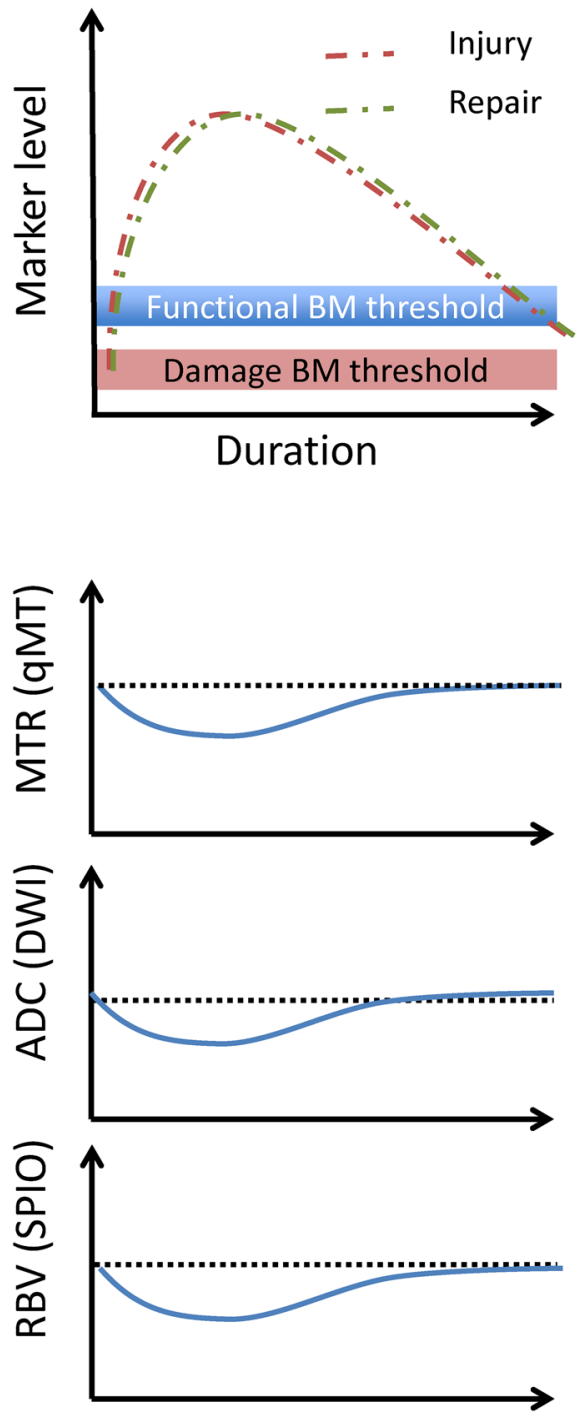

\section{Clinical AKI with Maladaptive Repair}


mechanism of AKI is complex and multifactorial, compelling us to consider the baseline renal function and time duration after kidney insult in heterogeneous patients when applying these damage biomarkers to clinical situations [157]. The performance of each damage biomarker depends on patient populations, timing of measurements, and selected cutoff values. Damage biomarkers themselves reflect the molecular and cellular events in AKI; despite their success in early AKI recognition, problems such as renal prediction and etiologies of AKI are yet to be solved $[152,158]$. It is important to choose biomarkers for each different AKI etiology in heterogeneous patient populations. Moreover, few available biomarkers reflect kidney repair/recovery [159].

Imaging techniques provide comprehensive and spatial information about actual pathophysiological events or functional changes in clinical AKI stages. Evaluating the additive value of using imaging techniques as physiological biomarkers along with damage biomarkers of AKI is necessary. Furthermore, we need to consider the effectiveness of imaging techniques for AKI versus the cost and time required, which depends on the modality, before they will be employed in clinical practice.

Patients presenting with positive urinary biomarkers have higher mortality in the long term, even if they do not meet 

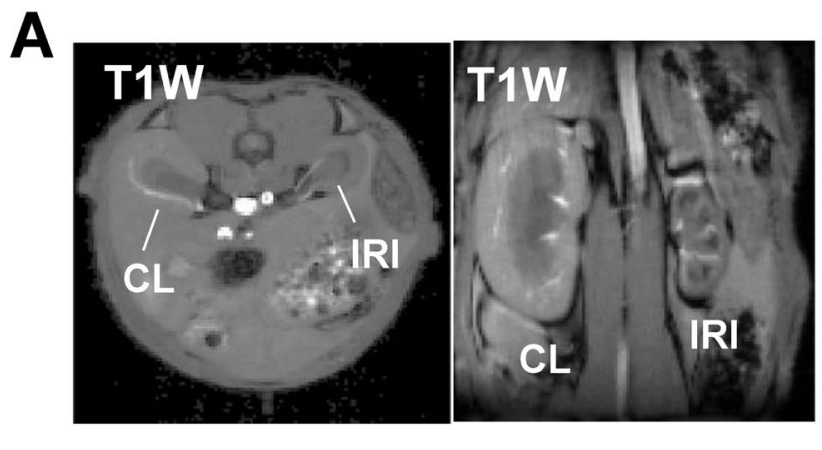

B
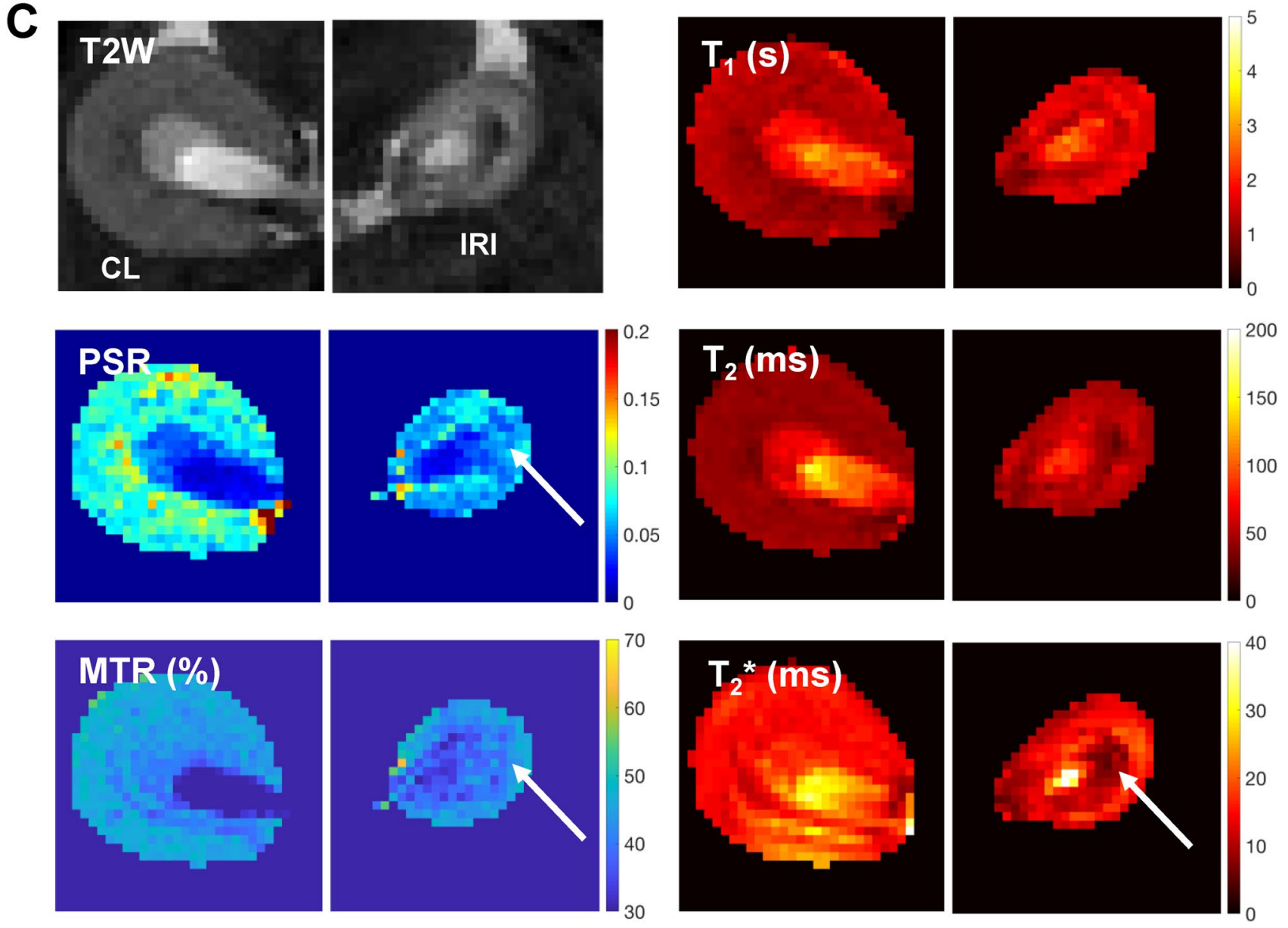

Fig. 3 Multi-parametric MRI maps of the mouse kidney after IRI. The left renal pedicle was clipped for $45 \mathrm{~min}$, and MRI was performed at 8 weeks after surgery. (a) $\mathrm{T}_{1}$-weighted (T1W) anatomical images showing shrinkage of the injured kidney. IRI ischemia-reperfusion injury, $C L$ contralateral kidney. (b) Renal histopathology of the kidney with IRI. Prominent tubular atrophy in the kidney with IRI was observed. Masson's trichrome staining is shown. Scale bar $=100 \mu \mathrm{m}$. (c) $\mathrm{T}_{2}$-weighted $(\mathrm{T} 2 \mathrm{~W})$ anatomical images, $\mathrm{T}_{1}$ maps,

the AKI criteria based on sCre levels or urine output [160]. Given the fact that hyperfiltration of less damaged nephrons could prevent the elevation of sCre, imaging techniques would be quite useful for assessing actual renal conditions of these "biomarker-positive creatinine-negative" patients.
$\mathrm{T}_{2}$ maps, $\mathrm{T}_{2} *$ maps, pool-size ratio (PSR) maps from quantitative magnetization transfer (qMT) modeling, and magnetization transfer ratio (MTR) maps based on images with and without magnetization transfer saturation (820 degree and RF offset $5000 \mathrm{~Hz}$ ). PSR and MTR signals and T2* signal intensity is regionally decreased in IRI kidney (arrows); the former indicates renal cell death/atrophy and the latter indicates hypoxia

Assessing the cause of reduction in several damage biomarkers to evaluate maladaptive repair after AKI would be another condition where imaging techniques are useful [161, 162]. Of note, it may be possible in the future to estimate kidney repair by combined monitoring of appropriate "repair 
biomarkers"; nevertheless, further translational and clinical investigation should be conducted before we can assess these repair biomarkers [163]. In the absence of available and widely recognized repair biomarkers, the use of current imaging techniques to evaluate the outcomes of AKI, including fibrosis, is reasonable. Several types of information provided by imaging techniques can help us explore the complex pathways of AKI. Among the advantages of imaging are that numerous techniques have already been applied to humans in clinical situations and that multiple parameters can be simultaneously assessed. Therefore, it is important to evaluate AKI using multi-parametric imaging or multiple imaging modalities [134] and to further investigate the value of imaging techniques using animal models (Figs. 2 and 3). Indeed, several recent studies have shown the value of this approach by comparing the findings of multi-parametric MRI with biochemical and/or renal pathology findings in animal models [134] and patients [164-166] with CKD.

\section{Conclusion}

Various new imaging techniques have been developed over the past decade, and their utility in AKI assessment has been shown in preclinical models. Nonetheless, their significance in clinical settings remains largely unknown. Further efforts are required to investigate the utility of imaging parameters or techniques in assessing the time course or pathophysiology of AKI using multi-parametric or multi-modality imaging and to determine their clinical significance by comparing or combining them with currently available biomarkers of AKI. These efforts will further advance our understanding about AKI and improve our treatment protocols.

Acknowledgements We thank the Center for Small Animal Imaging at the Vanderbilt University Institute of Imaging Science, as well as Drs. Mark deCaestecker and Tadashi Otsuka for the ischemia-reperfusion mouse study. This work was supported by Grants EB024525 (to J.C.G.) and DK114809 (to R.C.H. and T.T.) from the National Institutes of Health and was partially supported by the Japan Society for the Promotion of Science (JSPS Overseas Research Fellowships) and the Japan Agency for Medical Research and Development (20he0822003j0001) (to D.K.). This study is partially supported by Japan Agency for Medical Research and Development (AMED: 20he0822003j0001).

Author contributions All authors contributed to the study conception and design. Material preparation, literature search and data analysis were performed by DK and TT. The first draft of the manuscript was written by DK and TT, and all authors commented on previous versions of the manuscript. All authors read and approved the final manuscript.

\section{Declarations}

Conflicts of interest The authors have declared that no conflict of interest exists.
Research involving human participants and/or animals This article does not contain any studies with human participants or animals performed by any of the authors.

Informed consent Acquisition of informed consent is not applicable to this study.

Open Access This article is licensed under a Creative Commons Attribution 4.0 International License, which permits use, sharing, adaptation, distribution and reproduction in any medium or format, as long as you give appropriate credit to the original author(s) and the source, provide a link to the Creative Commons licence, and indicate if changes were made. The images or other third party material in this article are included in the article's Creative Commons licence, unless indicated otherwise in a credit line to the material. If material is not included in the article's Creative Commons licence and your intended use is not permitted by statutory regulation or exceeds the permitted use, you will need to obtain permission directly from the copyright holder. To view a copy of this licence, visit http://creativecommons.org/licenses/by/4.0/.

\section{References}

1. Chertow GM, Burdick E, Honour M, Bonventre JV, Bates DW. Acute kidney injury, mortality, length of stay, and costs in hospitalized patients. J Am Soc Nephrol. 2005;16(11):3365-70.

2. Palevsky PM, Molitoris BA, Okusa MD, Levin A, Waikar SS, Wald R, et al. Design of clinical trials in acute kidney injury: report from an NIDDK workshop on trial methodology. Clin J Am Soc Nephrol. 2012;7(5):844-50.

3. Siew ED, Davenport A. The growth of acute kidney injury: a rising tide or just closer attention to detail? Kidney Int. 2015;87(1):46-61.

4. Lo LJ, Go AS, Chertow GM, McCulloch CE, Fan D, Ordonez JD, et al. Dialysis-requiring acute renal failure increases the risk of progressive chronic kidney disease. Kidney Int. 2009;76(8):893-9.

5. Lu JC, Coca SG, Patel UD, Cantley L, Parikh CR. Searching for genes that matter in acute kidney injury: a systematic review. Clin J Am Soc Nephrol. 2009;4(6):1020-31.

6. Coca SG, Singanamala S, Parikh CR. Chronic kidney disease after acute kidney injury: a systematic review and meta-analysis. Kidney Int. 2012;81(5):442-8.

7. Wasung ME, Chawla LS, Madero M. Biomarkers of renal function, which and when? Clin Chim Acta. 2015;438:350-7.

8. Willmann JK, van Bruggen N, Dinkelborg LM, Gambhir SS. Molecular imaging in drug development. Nat Rev Drug Discov. 2008;7(7):591-607.

9. Dagher PC, Herget-Rosenthal S, Ruehm SG, Jo SK, Star RA, Agarwal R, et al. Newly developed techniques to study and diagnose acute renal failure. J Am Soc Nephrol. 2003;14(8):2188-98.

10. Uchino S, Kellum JA, Bellomo R, Doig GS, Morimatsu H, Morgera S, et al. Acute renal failure in critically ill patients: a multinational, multicenter study. JAMA. 2005;294(7):813-8.

11. Liano F, Pascual J. Epidemiology of acute renal failure: a prospective, multicenter, community-based study. Madrid Acute Renal Failure Study Group. Kidney Int. 1996;50(3):811-8.

12. Grams ME, Rabb H. The distant organ effects of acute kidney injury. Kidney Int. 2012;81(10):942-8.

13. Basile DP, Bonventre JV, Mehta R, Nangaku M, Unwin R, Rosner $\mathrm{MH}$, et al. Progression after AKI: understanding maladaptive 
repair processes to predict and identify therapeutic treatments. J Am Soc Nephrol. 2015;2015:5.

14. Rabb H, Griffin MD, McKay DB, Swaminathan S, Pickkers P, Rosner $\mathrm{MH}$, et al. Inflammation in AKI: current understanding, key questions, and knowledge gaps. J Am Soc Nephrol. 2016;27(2):371-9.

15. KDIGO (2012) Clinical practice guideline for acute kidney injury. Kidney Int Suppl 2(1):1-124

16. Molitoris BA, Sutton TA. Endothelial injury and dysfunction: role in the extension phase of acute renal failure. Kidney Int. 2004;66(2):496-9.

17. Sharfuddin AA, Molitoris BA. Pathophysiology of ischemic acute kidney injury. Nat Rev Nephrol. 2011;7(4):189-200.

18. Weisheit CK, Engel DR, Kurts C. Dendritic cells and macrophages: sentinels in the kidney. Clin J Am Soc Nephrol. 2015;10(10):1841-51.

19. Wang Y, Chang J, Yao B, Niu A, Kelly E, Breeggemann MC, et al. Proximal tubule-derived colony stimulating factor-1 mediates polarization of renal macrophages and dendritic cells, and recovery in acute kidney injury. Kidney Int. 2015;88(6):1274-82.

20. Zhang MZ, Yao B, Yang S, Jiang L, Wang S, Fan X, et al. CSF-1 signaling mediates recovery from acute kidney injury. J Clin Investig. 2012;122(12):4519-32.

21. Okusa MD, Rosner MH, Kellum JA, Ronco C. Therapeutic targets of human AKI: harmonizing human and animal AKI. J Am Soc Nephrol. 2015;2015:5.

22. Bonventre JV. Primary proximal tubule injury leads to epithelial cell cycle arrest, fibrosis, vascular rarefaction, and glomerulosclerosis. Kidney Int Suppl. 2014;4:39-44.

23. Schnell D, Darmon M. Bedside Doppler ultrasound for the assessment of renal perfusion in the ICU: advantages and limitations of the available techniques. Crit Ultrasound J. 2015;7(1):24.

24. Faubel S, Patel NU, Lockhart ME, Cadnapaphornchai MA. Renal relevant radiology: use of ultrasonography in patients with AKI. Clin J Am Soc Nephrol. 2014;9(2):382-94.

25. Liu C, Wang X. Clinical utility of ultrasonographic evaluation in acute kidney injury. Transl Androl Urol. 2020;9(3):1345-55.

26. Kaufman J, Dhakal M, Patel B, Hamburger R. Communityacquired acute renal failure. Am J Kid Dis. 1991;17(2):191-8.

27. Licurse A, Kim MC, Dziura J, Forman HP, Formica RN, Makarov DV, et al. Renal ultrasonography in the evaluation of acute kidney injury: developing a risk stratification framework. Arch Intern Med. 2010;170(21):1900-7.

28. Gamss R, Stein MW, Rispoli JM, Cohen HW, Roberts JH, Koenigsberg M, et al. What is the appropriate use of renal sonography in an inner-city population with new-onset acute kidney injury? J Ultrasound Med. 2015;34(9):1639-44.

29. Ninet S, Schnell D, Dewitte A, Zeni F, Meziani F, Darmon M. Doppler-based renal resistive index for prediction of renal dysfunction reversibility: a systematic review and meta-analysis. J Crit Care. 2015;30(3):629-35.

30. Hobson C, Ruchi R, Bihorac A. Perioperative acute kidney injury: risk factors and predictive strategies. Crit Care Clin. 2017;33(2):379-96.

31. Kararmaz A, Kemal Arslantas M, Cinel I. Renal resistive index measurement by transesophageal echocardiography: comparison with translumbar ultrasonography and relation to acute kidney injury. J Cardiothorac Vasc Anesth. 2015;29(4):875-80.

32. Wei K, Jayaweera AR, Firoozan S, Linka A, Skyba DM, Kaul S. Quantification of myocardial blood flow with ultrasound-induced destruction of microbubbles administered as a constant venous infusion. Circulation. 1998;97(5):473-83.

33. Schneider A, Johnson L, Goodwin M, Schelleman A, Bellomo R. Bench-to-bedside review: contrast enhanced ultrasonography-a promising technique to assess renal perfusion in the ICU. Crit Care. 2011;15(3):157.
34. Harrois A, Grillot N, Figueiredo S, Duranteau J. Acute kidney injury is associated with a decrease in cortical renal perfusion during septic shock. Crit Care. 2018;22(1):161.

35. Grenier N, Gennisson JL, Cornelis F, Le Bras Y, Couzi L. Renal ultrasound elastography. Diagn Interv Imaging. 2013;94(5):545-50.

36. Derieppe M, Delmas Y, Gennisson JL, Deminiere C, Placier S, Tanter M, et al. Detection of intrarenal microstructural changes with supersonic shear wave elastography in rats. Eur Radiol. 2012;22(1):243-50.

37. AbuRahma AF, Yacoub M. Renal imaging: duplex ultrasound, computed tomography angiography, magnetic resonance angiography, and angiography. Semin Vasc Surg. 2013;26(4):134-43.

38. Hou J, Fujino M, Cai S, Ding Q, Li XK. Noninvasive monitoring of mouse renal allograft rejection using micro-CT. Ann Surg Treatment Res. 2015;88(5):276-80.

39. Kubota R, Yamada S, Kubota K, Ishiwata K, Tamahashi N, Ido T. Intratumoral distribution of fluorine-18-fluorodeoxyglucose in vivo: high accumulation in macrophages and granulation tissues studied by microautoradiography. J Nucl Med. 1992;33(11):1972-80.

40. Katagiri D, Inoue T, Katsuma A, Masumoto S, Minami E, Hoshino T, et al. Large perinephric abscess in a patient on maintenance hemodialysis diagnosed by positron emission tomography combined with computed tomography (PET-CT). Clin Nephrol. 2010;73(2):163-6.

41. Katagiri D, Masumoto S, Katsuma A, Minami E, Hoshino T, Inoue $\mathrm{T}$, et al. Positron emission tomography combined with computed tomography (PET-CT) as a new diagnostic tool for acute tubulointerstitial nephritis (AIN) in oliguric or haemodialysed patients. Clin Kidney J. 2010;3(2):155-9.

42. Blackmur JP, Patel D, Kluth DC, Dhaun N. Utility of $18 \mathrm{~F}$-fluorodeoxyglucose positron emission tomography computed tomography in the diagnosis and management of aortitis. Circulation. 2015;132(20):1937-8.

43. Chopra S, Dharmaraja A, Mehta P, Colletti PM, Wassef H. FDG PET/CT images demonstrating epididymo-orchitis in a patient with HIV, acute kidney injury and known epididymo-orchitis on scrotal ultrasound. Clin Nucl Med. 2015;40(2):e171-2.

44. Perazella MA. Diagnosing drug-induced AIN in the hospitalized patient: a challenge for the clinician. Clin Nephrol. 2014;81(6):381-8.

45. Chen Q, Yu J, Rush BM, Stocker SD, Tan RJ, Kim K. Ultrasound super-resolution imaging provides a noninvasive assessment of renal microvasculature changes during mouse acute kidney injury. Kidney Int. 2020;98(2):355-65.

46. Vasquez SX, Gao F, Su F, Grijalva V, Pope J, Martin B, et al. Optimization of microCT imaging and blood vessel diameter quantitation of preclinical specimen vasculature with radiopaque polymer injection medium. PLoS ONE. 2011;6(4):e19099.

47. Ehling J, Bábíčková J, Gremse F, Klinkhammer BM, Baetke S, Knuechel R, et al. Quantitative micro-computed tomography imaging of vascular dysfunction in progressive kidney diseases. J Am Soc Nephrol. 2016;27(2):520-32.

48. Hlushchuk R, Haberthür D, Djonov V. Ex vivo microangioCT: advances in microvascular imaging. Vascul Pharmacol. 2019;112:2-7.

49. Kramann R, Tanaka M, Humphreys BD. Fluorescence microangiography for quantitative assessment of peritubular capillary changes after AKI in mice. J Am Soc Nephrol. 2014;25(9):1924-31.

50. Hueper K, Rong S, Gutberlet M, Hartung D, Mengel M, Lu X, et al. T2 relaxation time and apparent diffusion coefficient for noninvasive assessment of renal pathology after acute kidney 
injury in mice: comparison with histopathology. Invest Radiol. 2013;48(12):834-42.

51. Hueper K, Peperhove M, Rong S, Gerstenberg J, Mengel M, Meier M, et al. T1-mapping for assessment of ischemia-induced acute kidney injury and prediction of chronic kidney disease in mice. Eur Radiol. 2014;24(9):2252-60.

52. Parvin N, Charlton J, Baldelomar E, Derakhshan J. Mapping vascular and glomerular pathology in a rabbit model of neonatal acute kidney injury using MRI. Anatom Rec. 2020;2020:5.

53. Charlton JR, Xu Y, Wu T, deRonde KA, Hughes JL, Dutta S, et al. Magnetic resonance imaging accurately tracks kidney pathology and heterogeneity in the transition from acute kidney injury to chronic kidney disease. Kidney Int. 2021;99(1):173-85.

54. Prasad PV. Functional MRI of the kidney: tools for translational studies of pathophysiology of renal disease. Am J Physiol Renal Physiol. 2006;290(5):F958-74.

55. Takahashi T, Wang F, Quarles CC. Current MRI techniques for the assessment of renal disease. Curr Opin Nephrol Hypertens. 2015;24(3):217-23.

56. Heyman SN, Rosenberger C, Rosen S. Acute kidney injury: lessons from experimental models. Contrib Nephrol. 2011;169:286-96.

57. Schneider AG, Goodwin MD, Bellomo R. Measurement of kidney perfusion in critically ill patients. Crit Care. 2013;17(2):220.

58. Wu CJ, Bao ML, Wang Q, Wang XN, Liu XS, Shi HB, et al. Acute kidney damage induced by low- and iso-osmolar contrast media in rats: comparison study with physiologic MRI and histologic-gene examination. J Magn Reso Imaging. 2017;45(1):291-302.

59. Privratsky JR, Wang N, Qi Y, Ren J, Morris BT, Hunting JC, et al. Dynamic contrast-enhanced MRI promotes early detection of toxin-induced acute kidney injury. Am J Physiol Renal Physiol. 2019;316(2):F351-9.

60. Niendorf T, Seeliger E, Cantow K, Flemming B, Waiczies S, Pohlmann A. Probing renal blood volume with magnetic resonance imaging. Acta Physiol (Oxf). 2020;228(4):e13435.

61. Ferguson MA, Waikar SS. Established and emerging markers of kidney function. Clin Chem. 2012;58(4):680-9.

62. Poff JA, Hecht EM, Ramchandani P. Renal imaging in patients with renal impairment. Curr Urol Rep. 2011;12(1):24-33.

63. Macedo E, Mehta RL. Measuring renal function in critically ill patients: tools and strategies for assessing glomerular filtration rate. Curr Opin Crit Care. 2013;19(6):560-6.

64. Storey P, Ji L, Li LP, Prasad PV. Sensitivity of USPIO-enhanced $\mathrm{R} 2$ imaging to dynamic blood volume changes in the rat kidney. J Magn Reson Imaging. 2011;33(5):1091-9.

65. Wang F, Jiang RT, Tantawy MN, Borza DB, Takahashi K, Gore JC, et al. Repeatability and sensitivity of high resolution blood volume mapping in mouse kidney disease. J Magn Reson Imaging. 2014;39(4):866-71.

66. Neuwelt EA, Hamilton BE, Varallyay CG, Rooney WR, Edelman $\mathrm{RD}$, Jacobs PM, et al. Ultrasmall superparamagnetic iron oxides (USPIOs): a future alternative magnetic resonance (MR) contrast agent for patients at risk for nephrogenic systemic fibrosis (NSF)? Kidney Int. 2009;75(5):465-74.

67. Menshikh A, Scarfe L, Delgado R, Finney C, Zhu Y, Yang H, et al. Capillary rarefaction is more closely associated with CKD progression after cisplatin, rhabdomyolysis, and ischemia-reperfusion-induced AKI than renal fibrosis. Am J Physiol Renal Physiol. 2019;317(5):F1383-97.

68. Ittrich H, Lange C, Togel F, Zander AR, Dahnke H, Westenfelder $\mathrm{C}$, et al. In vivo magnetic resonance imaging of iron oxidelabeled, arterially-injected mesenchymal stem cells in kidneys of rats with acute ischemic kidney injury: detection and monitoring at 3T. J Magn Reson Imaging. 2007;25(6):1179-91.
69. Hu L, Chen J, Yang X, Senpan A, Allen JS, Yanaba N, et al. Assessing intrarenal nonperfusion and vascular leakage in acute kidney injury with multinuclear (1) H/(19) F MRI and perfluorocarbon nanoparticles. Magn Reson Med. 2014;71(6):2186-96.

70. Moore JK, Chen J, Pan H, Gaut JP, Jain S, Wickline SA. Quantification of vascular damage in acute kidney injury with fluorine magnetic resonance imaging and spectroscopy. Magn Reson Med. 2018;79(6):3144-53.

71. Cutajar M, Thomas DL, Banks T, Clark CA, Golay X, Gordon I. Repeatability of renal arterial spin labelling MRI in healthy subjects. Magma (New York, NY). 2012;25(2):145-53.

72. Zhou HY, Chen TW, Zhang XM. Functional magnetic resonance imaging in acute kidney injury: present status. Biomed Res Int. 2016;2016:2027370.

73. Karger N, Biederer J, Lusse S, Grimm J, Steffens J, Heller M, et al. Quantitation of renal perfusion using arterial spin labeling with FAIR-UFLARE. Magn Reson Imaging. 2000;18(6):641-7.

74. Lanzman RS, Wittsack HJ, Martirosian P, Zgoura P, Bilk P, Kropil P, et al. Quantification of renal allograft perfusion using arterial spin labeling MRI: initial results. Eur Radiol. 2010;20(6):1485-91.

75. Tewes S, Gueler F, Chen R, Gutberlet M, Jang MS, Meier M, et al. Functional MRI for characterization of renal perfusion impairment and edema formation due to acute kidney injury in different mouse strains. PLoS ONE. 2017;12(3):e0173248.

76. Keramida G, James JM, Prescott MC, Peters AM. Pitfalls and limitations of radionuclide renal imaging in adults. Semin Nucl Med. 2015;45(5):428-39.

77. Durand E, Chaumet-Riffaud P, Grenier N. Functional renal imaging: new trends in radiology and nuclear medicine. Semin Nucl Med. 2011;41(1):61-72.

78. Tantawy MN, Jiang R, Wang F, Takahashi K, Peterson TE, Zemel $\mathrm{D}$, et al. Assessment of renal function in mice with unilateral ureteral obstruction using 99mTc-MAG3 dynamic scintigraphy. BMC Nephrol. 2012;13:168.

79. Roberts J, Chen B, Curtis LM, Agarwal A, Sanders PW, Zinn KR. Detection of early changes in renal function using $99 \mathrm{mTc}-$ MAG3 imaging in a murine model of ischemia-reperfusion injury. Am J Physiol Renal Physiol. 2007;293(4):F1408-12.

80. Herrler T, Tischer A, Meyer A, Feiler S, Guba M, Nowak S, et al. The intrinsic renal compartment syndrome: new perspectives in kidney transplantation. Transplantation. 2010;89(1):40-6.

81. Weyer K, Nielsen R, Petersen SV, Christensen EI, Rehling M, Birn H. Renal uptake of $99 \mathrm{mTc}$-dimercaptosuccinic acid is dependent on normal proximal tubule receptor-mediated endocytosis. J Nucl Med. 2013;54(1):159-65.

82. Jouret F, Walrand S, Parreira KS, Courtoy PJ, Pauwels S, Devuyst $\mathrm{O}$, et al. Single photon emission-computed tomography (SPECT) for functional investigation of the proximal tubule in conscious mice. Am J Physiol Renal Physiol. 2010;298(2):F454-60.

83. Sedaghat Z, Fatemikia H, Tanha K, Zahiri M, Assadi M. Scintigraphic evaluation of remote pre-conditioning protection against unilateral renal ischemia/reperfusion injury in rats: a longitudinal study. Int Urol Nephrol. 2019;51(11):2083-9.

84. Brezis M, Rosen S. Hypoxia of the renal medulla-its implications for disease. N Engl J Med. 1995;332(10):647-55.

85. O'Connor PM, Evans RG. Structural antioxidant defense mechanisms in the mammalian and nonmammalian kidney: different solutions to the same problem? Am J Physiol Regul Integr Comp Physiol. 2010;299(3):R723-7.

86. Venkatachalam MA, Bernard DB, Donohoe JF, Levinsky NG. Ischemic damage and repair in the rat proximal tubule: differences among the S1, S2, and S3 segments. Kidney Int. 1978;14(1):31-49. 
87. Sugden MC, Holness MJ, Donald E, Lall H. Substrate interactions in the short- and long-term regulation of renal glucose oxidation. Metabol Clin Exper. 1999;48(6):707-15.

88. Simon N, Hertig A. Alteration of fatty acid oxidation in tubular epithelial cells: from acute kidney injury to renal fibrogenesis. Front Med. 2015;2:52.

89. Nangaku M. Chronic hypoxia and tubulointerstitial injury: a final common pathway to end-stage renal failure. J Am Soc Nephrol. 2006;17(1):17-25.

90. Ogawa S, Lee TM, Kay AR, Tank DW. Brain magnetic resonance imaging with contrast dependent on blood oxygenation. PNAS. 1990;87(24):9868-72.

91. Pohlmann A, Cantow K, Huelnhagen T, Grosenick D, Dos Santos PJ, Boehmert L, et al. Experimental MRI monitoring of renal blood volume fraction variations en route to renal magnetic resonance oximetry. Tomography. 2017;3(4):188-200.

92. Prasad PV, Edelman RR, Epstein FH. Noninvasive evaluation of intrarenal oxygenation with BOLD MRI. Circulation. 1996;94(12):3271-5.

93. Li LP, Halter S, Prasad PV. Blood oxygen level-dependent MR imaging of the kidneys. Magn Reson Imaging Clin N Am. 2008;16(4):613-25.

94. Zhang B, Wang Y, Wang C, Wang H, Kong H, Zhang J, et al. Comparison of blood oxygen level-dependent imaging and diffusion-weighted imaging in early diagnosis of acute kidney injury in animal models. J Magn Reson Imaging. 2019;50(3):719-24.

95. Wang Z, Liu H, Meng H, Zhang D. Application of diffusion tensor imaging and blood oxygenation level-dependent magnetic resonance imaging to assess bilateral renal function induced by Iohexol in rabbits. BMC Nephrol. 2020;21(1):210.

96. Hofmann L, Simon-Zoula S, Nowak A, Giger A, Vock P, Boesch $\mathrm{C}$, et al. BOLD-MRI for the assessment of renal oxygenation in humans: acute effect of nephrotoxic xenobiotics. Kidney Int. 2006;70(1):144-50.

97. Pohlmann A, Hentschel J, Fechner M, Hoff U, Bubalo G, Arakelyan K, et al. High temporal resolution parametric MRI monitoring of the initial ischemia/reperfusion phase in experimental acute kidney injury. PLoS ONE. 2013;8(2):e57411.

98. Liu G, Han F, Xiao W, Wang Q, Xu Y, Chen J. Detection of renal allograft rejection using blood oxygen level-dependent and diffusion weighted magnetic resonance imaging: a retrospective study. BMC Nephrol. 2014;15:158.

99. Sadowski EA, Fain SB, Alford SK, Korosec FR, Fine J, Muehrer $\mathrm{R}$, et al. Assessment of acute renal transplant rejection with blood oxygen level-dependent MR imaging: initial experience. Radiology. $2005 ; 236(3): 911-9$.

100. Neugarten J. Renal BOLD-MRI and assessment for renal hypoxia. Kidney Int. 2012;81(7):613-4.

101. Michaely HJ, Metzger L, Haneder S, Hansmann J, Schoenberg SO, Attenberger UI. Renal BOLD-MRI does not reflect renal function in chronic kidney disease. Kidney Int. 2012;81(7):684-9.

102. Wang X, Sukstanskii AL, Yablonskiy DA. Optimization strategies for evaluation of brain hemodynamic parameters with qBOLD technique. Magn Reson Med. 2013;69(4):1034-43.

103. Christen T, Lemasson B, Pannetier N, Farion R, Segebarth C, Remy C, et al. Evaluation of a quantitative blood oxygenation level-dependent (qBOLD) approach to map local blood oxygen saturation. NMR Biomed. 2011;24(4):393-403.

104. Domsch S, Mie MB, Wenz F, Schad LR. Non-invasive multiparametric qBOLD approach for robust mapping of the oxygen extraction fraction. Z Med Phys. 2014;24(3):231-42.

105. Milman Z, Axelrod JH, Heyman SN, Nachmansson N, Abramovitch R. Assessment with unenhanced MRI techniques of renal morphology and hemodynamic changes during acute kidney injury and chronic kidney disease in mice. Am J Nephrol. 2014;39(3):268-78.

106. Hirakawa Y, Yoshihara T, Kamiya M, Mimura I, Fujikura $\mathrm{D}$, Masuda T, et al. Quantitating intracellular oxygen tension in vivo by phosphorescence lifetime measurement. Sci Rep. 2015;5:17838.

107. Kong H, Wang C, Gao F, Zhang X, Yang M, Yang L, et al. Early assessment of acute kidney injury using targeted field of view diffusion-weighted imaging: an in vivo study. Magn Reson Imaging. 2019;57:1-7.

108. Zhang B, Dong Y, Guo B, Chen W, Ouyang F, Lian Z, et al. Application of noninvasive functional imaging to monitor the progressive changes in kidney diffusion and perfusion in contrast-induced acute kidney injury rats at 3.0 T. Abdom Radiol (NY). 2018;43(3):655-62.

109. Wang C, Zhang B, Wang H, Kong H, Gao F, Wang X, et al. A feasibility study of using noninvasive renal oxygenation imaging for the early assessment of ischemic acute kidney injury in an embolization model. Magn Reson Imaging. 2019;63:178-84.

110. Inoue $\mathrm{T}$, Kozawa $\mathrm{E}$, Okada $\mathrm{H}$, Inukai K, Watanabe S, Kikuta $\mathrm{T}$, et al. Noninvasive evaluation of kidney hypoxia and fibrosis using magnetic resonance imaging. J Am Soc Nephrol. 2011;22(8):1429-34.

111. Eisenberger U, Thoeny HC, Binser T, Gugger M, Frey FJ, Boesch C, et al. Evaluation of renal allograft function early after transplantation with diffusion-weighted MR imaging. Eur Radiol. 2010;20(6):1374-83.

112. Hueper K, Gutberlet M, Rodt T, Gwinner W, Lehner F, Wacker $F$, et al. Diffusion tensor imaging and tractography for assessment of renal allograft dysfunction-initial results. Eur Radiol. 2011;21(11):2427-33.

113. Binser T, Thoeny HC, Eisenberger U, Stemmer A, Boesch C, Vermathen P. Comparison of physiological triggering schemes for diffusion-weighted magnetic resonance imaging in kidneys. J Magn Reson Imaging. 2010;31(5):1144-50.

114. Liang L, Chen WB, Chan KW, Li YG, Zhang B, Liang CH, et al. Using intravoxel incoherent motion MR imaging to study the renal pathophysiological process of contrast-induced acute kidney injury in rats: Comparison with conventional DWI and arterial spin labelling. Eur Radiol. 2016;26(6):1597-605.

115. Cheung JS, Fan SJ, Chow AM, Zhang J, Man K, Wu EX. Diffusion tensor imaging of renal ischemia reperfusion injury in an experimental model. NMR Biomed. 2010;23(5):496-502.

116. Zhang ZH, Wei F, Vaziri ND, Cheng XL, Bai X, Lin RC, et al. Metabolomics insights into chronic kidney disease and modulatory effect of rhubarb against tubulointerstitial fibrosis. Sci Rep. 2015;5:14472.

117. Clatworthy MR, Kettunen MI, Hu DE, Mathews RJ, Witney $\mathrm{TH}$, Kennedy BW, et al. Magnetic resonance imaging with hyperpolarized [1,4-(13)C2]fumarate allows detection of early renal acute tubular necrosis. PNAS. 2012;109(33):13374-9.

118. Vinogradov E, Sherry AD, Lenkinski RE. CEST: from basic principles to applications, challenges and opportunities. J Magn Reson (San Diego, Calif: 1997). 2013;229:155-72.

119. Wang F, Kopylov D, Zu Z, Takahashi K, Wang S, Quarles $\mathrm{CC}$, et al. Mapping murine diabetic kidney disease using chemical exchange saturation transfer MRI. Magn Reson Med. 2016;76(5):1531-41.

120. Longo DL, Busato A, Lanzardo S, Antico F, Aime S. Imaging the $\mathrm{pH}$ evolution of an acute kidney injury model by means of iopamidol, a MRI-CEST pH-responsive contrast agent. Magn Reson Med. 2013;70(3):859-64.

121. Irrera P, Consolino L, Cutrin JC, Zöllner FG, Longo DL. Dual assessment of kidney perfusion and $\mathrm{pH}$ by exploiting a dynamic CEST-MRI approach in an acute kidney ischemia-reperfusion injury murine model. NMR Biomed. 2020;33(6):e4287. 
122. Liu J, Han Z, Chen G, Li Y, Zhang J, Xu J, et al. CEST MRI of sepsis-induced acute kidney injury. NMR Biomed. 2018;31(8):e3942.

123. Reuter S, Schnockel U, Edemir B, Schroter R, Kentrup D, Pavenstadt $\mathrm{H}$, et al. Potential of noninvasive serial assessment of acute renal allograft rejection by $18 \mathrm{~F}-\mathrm{FDG}$ PET to monitor treatment efficiency. J Nucl Med. 2010;51(10):1644-52.

124. Pajenda S, Rasul S, Hacker M, Wagner L, Geist BK. Dynamic 2-deoxy-2[18F] fluoro-D-glucose PET/MRI in human renal allotransplant patients undergoing acute kidney injury. Sci Rep. 2020;10(1):8270.

125. Grabner A, Kentrup D, Edemir B, Sirin Y, Pavenstadt H, Schlatter E, et al. PET with 18F-FDG-labeled T lymphocytes for diagnosis of acute rat renal allograft rejection. J Nucl Med. 2013;54(7):1147-53.

126. Kaissling B, Lehir M, Kriz W. Renal epithelial injury and fibrosis. Biochem Biophys Acta. 2013;1832(7):931-9.

127. Skrypnyk NI, Harris RC, de Caestecker MP. Ischemia-reperfusion model of acute kidney injury and post injury fibrosis in mice. J Vis Exp. 2013;2013:78.

128. Yang L, Besschetnova TY, Brooks CR, Shah JV, Bonventre JV. Epithelial cell cycle arrest in G2/M mediates kidney fibrosis after injury. Nature Med. 2010;16(5):535-43.

129. Katagiri D, Noiri E, Matsuura R, Harris RC. Acute kidney injury; transition to chronic kidney disease. Hum Pathobiochem. 2018;2018:269-77.

130. Katagiri D, Hamasaki Y, Doi K, Negishi K, Sugaya T, Nangaku $\mathrm{M}$, et al. Interstitial renal fibrosis due to multiple cisplatin treatments is ameliorated by semicarbazide-sensitive amine oxidase inhibition. Kidney Int. 2015;89(2):374-85.

131. Togao O, Doi S, Kuro M, Masaki T, Yorioka N, Takahashi M. Assessment of renal fibrosis with diffusion-weighted MR imaging: study with murine model of unilateral ureteral obstruction. Radiology. 2010;255(3):772-80.

132. Jiang K, Ferguson CM, Lerman LO. Noninvasive assessment of renal fibrosis by magnetic resonance imaging and ultrasound techniques. Trans1 Res. 2019;209:105-20.

133. Leung G, Kirpalani A, Szeto SG, Deeb M, Foltz W, Simmons CA, et al. Could MRI be used to image kidney fibrosis? A review of recent advances and remaining barriers. Clin J Am Soc Nephrol. 2017;12(6):1019-28.

134. Jiang K, Ponzo TA, Tang H, Mishra PK, Macura SI, Lerman LO. Multiparametric MRI detects longitudinal evolution of folic acid-induced nephropathy in mice. Am J Physiol Renal Physiol. 2018;315(5):F1252-60.

135. Wang F, Katagiri D, Li K, Takahashi K, Wang S, Nagasaka S, et al. Assessment of renal fibrosis in murine diabetic nephropathy using quantitative magnetization transfer MRI. Magn Reson Med. 2018;80(6):2655-69.

136. Wang F, Wang S, Zhang Y, Li K, Harris RC, Gore JC, et al. Noninvasive quantitative magnetization transfer MRI reveals tubulointerstitial fibrosis in murine kidney. NMR Biomed. 2019;32(11):e4128.

137. Jiang K, Ferguson CM, Woollard JR, Landes VL, Krier JD, Zhu X, et al. Magnetization transfer imaging is unaffected by decreases in renal perfusion in swine. Invest Radiol. 2019;54(11):681-8.

138. Korsmo MJ, Ebrahimi B, Eirin A, Woollard JR, Krier JD, Crane JA, et al. Magnetic resonance elastography noninvasively detects in vivo renal medullary fibrosis secondary to swine renal artery stenosis. Invest Radiol. 2013;48(2):61-8.

139. Hu G, Liang W, Wu M, Lai C, Mei Y, Li Y, et al. Comparison of T1 mapping and T1rho values with conventional diffusionweighted imaging to assess fibrosis in a rat model of unilateral ureteral obstruction. Acad Radiol. 2019;26(1):22-9.
140. Wang F, Colvin DC, Wang S, Li H, Zu Z, Harris RC, et al. Spinlock relaxation rate dispersion reveals spatiotemporal changes associated with tubulointerstitial fibrosis in murine kidney. Magn Reson Med. 2020;84:2074-87.

141. Rapacchi S, Smith RX, Wang Y, Yan L, Sigalov V, Krasileva KE, et al. Towards the identification of multi-parametric quantitative MRI biomarkers in lupus nephritis. Magn Reson Imaging. 2015;33(9):1066-74.

142. Maril N, Margalit R, Rosen S, Heyman SN, Degani H. Detection of evolving acute tubular necrosis with renal 23Na MRI: studies in rats. Kidney Int. 2006;69(4):765-8.

143. Kopp C, Linz P, Wachsmuth L, Dahlmann A, Horbach T, Schofl $\mathrm{C}$, et al. (23)Na magnetic resonance imaging of tissue sodium. Hypertension. 2012;59(1):167-72.

144. Atthe BK, Babsky AM, Hopewell PN, Phillips CL, Molitoris BA, Bansal N. Early monitoring of acute tubular necrosis in the rat kidney by $23 \mathrm{Na}-\mathrm{MRI}$. Am J Physiol Renal Physiol. 2009;297(5):F1288-98.

145. Akhtar AM, Schneider JE, Chapman SJ, Jefferson A, Digby $\mathrm{JE}$, Mankia $\mathrm{K}$, et al. In vivo quantification of VCAM-1 expression in renal ischemia reperfusion injury using noninvasive magnetic resonance molecular imaging. PLoS ONE. 2010;5(9):e12800

146. Olson ES, Ortac I, Malone C, Esener S, Mattrey R. Ultrasound detection of regional oxidative stress in deep tissues using novel enzyme loaded nanoparticles. Adv Healthc Mater. 2017;6:5.

147. Hoyt K, Warram JM, Wang D, Ratnayaka S, Traylor A, Agarwal A. Molecular ultrasound imaging of tissue inflammation using an animal model of acute kidney injury. Mol Imaging Biol. 2015;17(6):786-92.

148. Huang J, Li J, Lyu Y, Miao Q, Pu K. Molecular optical imaging probes for early diagnosis of drug-induced acute kidney injury. Nat Mater. 2019;18(10):1133-43.

149. Cheng P, Chen W, Li S, He S, Miao Q, Pu K. Fluoro-photoacoustic polymeric renal reporter for real-time dual imaging of acute kidney injury. Adv Mater. 2020;32(17):e1908530.

150. Perazella MA, Coca SG. Three feasible strategies to minimize kidney injury in "incipient AKI." Nat Rev Nephrol. 2013;9(8):484-90.

151. Himmelfarb J, Joannidis M, Molitoris B, Schietz M, Okusa MD Warnock D, et al. Evaluation and initial management of acute kidney injury. Clin J Am Soc Nephrol. 2008;3(4):962-7.

152. Huen SC, Parikh CR. Molecular phenotyping of clinical AKI with novel urinary biomarkers. Am J Physiol Renal Physiol. 2015;309(5):F406-13.

153. Endre ZH. Using biomarkers for acute kidney injury: barriers and solutions. Nephron Clin Pract. 2014;127(1-4):180-4.

154. Parikh CR, Coca SG, Thiessen-Philbrook H, Shlipak MG, Koyner JL, Wang Z, et al. Postoperative biomarkers predict acute kidney injury and poor outcomes after adult cardiac surgery. J Am Soc Nephrol. 2011;22(9):1748-57.

155. Parikh CR, Devarajan P, Zappitelli M, Sint K, Thiessen-Philbrook $\mathrm{H}, \mathrm{Li} \mathrm{S}$, et al. Postoperative biomarkers predict acute kidney injury and poor outcomes after pediatric cardiac surgery. J Am Soc Nephrol. 2011;22(9):1737-47.

156. Parikh CR, Thiessen-Philbrook H, Garg AX, Kadiyala D, Shlipak MG, Koyner JL, et al. Performance of kidney injury molecule-1 and liver fatty acid-binding protein and combined biomarkers of AKI after cardiac surgery. Clin J Am Soc Nephrol. 2013;8(7):1079-88.

157. Endre ZH, Pickering JW, Walker RJ, Devarajan P, Edelstein $\mathrm{CL}$, Bonventre JV, et al. Improved performance of urinary biomarkers of acute kidney injury in the critically ill by stratification for injury duration and baseline renal function. Kidney Int. 2011;79(10):1119-30. 
158. Alge JL, Arthur JM. Biomarkers of AKI: a review of mechanistic relevance and potential therapeutic implications. Clin J am Soc Nephrol. 2015;10(1):147-55.

159. Parikh CR, Liu C, Mor MK, Palevsky PM, Kaufman JS, Thiessen Philbrook H, et al. Kidney biomarkers of injury and repair as predictors of contrast-associated AKI: a substudy of the PRESERVE trial. Am J Kidney Dis. 2020;75(2):187-94.

160. Coca SG, Garg AX, Thiessen-Philbrook H, Koyner JL, Patel UD, Krumholz HM, et al. Urinary biomarkers of AKI and mortality 3 years after cardiac surgery. J Am Soc Nephrol. 2014;25(5):1063-71.

161. Srisawat N, Wen X, Lee M, Kong L, Elder M, Carter M, et al. Urinary biomarkers and renal recovery in critically ill patients with renal support. Clin J Am Soc Nephrol. 2011;6(8):1815-23.

162. Meersch M, Schmidt C, Van Aken H, Martens S, Rossaint J, Singbartl K, et al. Urinary TIMP-2 and IGFBP7 as early biomarkers of acute kidney injury and renal recovery following cardiac surgery. PLoS ONE. 2014;9(3):e93460.

163. Kashani K, Kellum JA. Novel biomarkers indicating repair or progression after acute kidney injury. Curr Opin Nephrol Hypertens. $2015 ; 24(1): 21-7$.
164. Buchanan CE, Mahmoud H, Cox EF, McCulloch T, Prestwich BL, Taal MW, et al. Quantitative assessment of renal structural and functional changes in chronic kidney disease using multiparametric magnetic resonance imaging. Nephrol Dial Transplant. 2020;35(6):955-64.

165. Cox EF, Buchanan CE, Bradley CR, Prestwich B, Mahmoud H, Taal M, et al. Multiparametric renal magnetic resonance imaging: validation, interventions, and alterations in chronic kidney disease. Front Physiol. 2017;8:696.

166. Bane O, Hectors SJ, Gordic S, Kennedy P, Wagner M, Weiss A, et al. Multiparametric magnetic resonance imaging shows promising results to assess renal transplant dysfunction with fibrosis. Kidney Int. 2020;97(2):414-20.

Publisher's Note Springer Nature remains neutral with regard to jurisdictional claims in published maps and institutional affiliations. 